\title{
ethic@ \\ HERESIA E IDIOTIA SEGUNDO SCHOPENHAUER: HERMENÊUTICA, CETICISMO E SIGNIFICAÇÃO MORAL DO MUNDO
}

\author{
HERESY AND IDIOCY ACCORDING TO SCHOPENHAUER: \\ HERMENEUTICS, SKEPTICISM AND MORAL SIGNIFICANCE OF \\ THE WORLD
}

RUY DE CARVALHO RODRIGUES Jr ${ }^{1}$. (UECE, Brasil)

\begin{abstract}
RESUMO
O artigo pretende apresentar e defender a viabilidade de uma leitura da obra de Schopenhauer, em especial de sua metafisica da natureza, em uma dupla perspectiva: hermenêutica e cética; e em uma quádrupla frente: 1) levando a sério a distinção schopenhaueriana entre ser subjetivo e ser objetivo, bem como, no interior deste último, entre consideração subjetiva e objetiva; 2) a partir daquilo que chamo de tese da inteligibilidade inversa; 3) concebendo o processo de objetivação da Vontade nos moldes de uma teoria dos mundos possíveis; 4) compreendendo a matéria (Materie) como noção-limite da filosofia schopenhaueriana e, esta, como uma filosofia do limite. Trata-se menos de conceber um Schopenhauer hermenêuta ou cético que tentar estabelecer um diálogo entre sua obra e uma certa concepção de hermenêutica e ceticismo. Diálogo que seria capaz de encaminhar possíveis soluções para alguns problemas que sua filosofia sempre teve dificuldade em enfrentar, como a significação profunda da noção de Vontade e as implicações cosmológicas a ela ligados.
\end{abstract}

Palavras-chave: Metafísica. Hermenêutica. Ceticismo. Limite.

\begin{abstract}
The article aims to present and defend the viability of a reading on Schopenhauer's work, especially his metaphysics of nature, in a double perspective: hermeneutics and skeptical, and a four-fold front: 1) taking seriously Schopenhauer's distinction between: subjective and objective being, as well as that, there included, between subjective and objective consideration; 2) starting from what I call: the theory of the inverse intelligibility; 3 ) conceiving the process of objectification of Will in terms of a theory of possible worlds; 4) understanding the matter (Materie) as a limit concept of Schopenhauer's philosophy and that one as a philosophy of the limit. This is less about conceiving Schopenhauer as hermeneut or skeptical, than to develop a dialog between his work and a certain conception of hermeneutics and skepticism. Such dialog, able to forward a solution to some problems that his philosophy has always had difficult to deal with, such as the inner significance of the notion of Will and the cosmological implications attached to it. Key words: Metaphysics. Hermeneutics. Skepticism. Limit.
\end{abstract}




\section{Introdução}

Esse título, provavelmente, causará desconforto ou uma certa estranheza ao frequentador habitual dos textos de Schopenhauer. Por um lado, o autor nunca se refere desta maneira ao, por assim dizer, estatuto de sua filosofia; por outro lado, sugerir algum tipo de interlocução entre o pensamento schopenhaueriano e a hermenêutica e o ceticismo, talvez provoque a suspeita da presença de uma certa ingenuidade, quiçá de uma possível ignorância do intérprete.

Quanto ao ceticismo, a coisa seria, para lembrarmos Fichte, clara como o sol? revelaria, ao levarmos Schopenhauer a sério, uma certa esperteza e uma certa idiotia. Esperto e idiota seria aquele, aos olhos de Schopenhauer, que tentasse torcer seu pensamento em direção ao território cético. Em um texto do segundo volume dos Parerga e em uma carta a Frauenstädt (de 30 de outubro de 1851), podemos vislumbrar a possível posição de Schopenhauer em relação àquilo que pretendo sugerir. Ele diria, penso: 1) que sou (eu, Ruy) um idiota; e que 2) esperteza é coisa de político, que quando se trata do filósofo e do filosofar, deve-se declinar do direito de se ser esperto.

Quanto à hermenêutica, o caso, talvez, seja até mais grave, uma vez que, por assim dizer, roçaria o religioso. Ao crermos em Domenico Fazio, haveria algo como uma Escola de Schopenhauer. Escola que teria um duplo sentido: Escola em sentido estricto e Escola em sentido lato. A primeira, partiria do "batismo" realizado por Schopenhauer, em seu epistolário, de seus discípulos: aqueles que interpretam e divulgam sua filosofia são "batizados" de Apóstolos; aqueles que, além disso, escrevem sobre ela e enfrentam seus adversários, são denominados de Evangelistas. A segunda, Escola em sentido lato, estaria dividida entre metafísicos, heréticos e pais fundadores. Os primeiros, aqueles que, por perceberem que a pedra fundamental da filosofia schopenhaueriana reside em sua metafísica, refletem sobre e enfrentam os problemas encontrados no interior da mesma. Os heréticos, como aqui me apresento, são aqueles que se distanciam da ortodoxia da letra, mas insistem em se auto-compreenderem como schopenhauerianos ou se reconhecerem como herdeiros e pertencentes à "tradição" aberta por Schopenhauer. Os últimos, os assim chamados de pais fundadores, são os pioneiros, os intérpretes de primeira hora, e assim por diante. Aqui, apontarei uma via de interpretação herética, heterodoxa, talvez, para alguns, equivocada, e mesmo, no limite, absurda; mas o heterodoxo, o equivocado e até o absurdo podem, sim, às vezes, 
fazer sentido e, em alguns casos favoráveis, ajudar-nos no enfrentamento de problemas relevantes.

\section{Da heresia: o caso hermenêutico}

Há alguns anos venho conversando e testando minha leitura, na falta de termo melhor, hermenêutica, da filosofia de Schopenhauer. Ela surgiu da necessidade ineludível que tenho de compreender a significação e o alcance da distinção toto genere, existente entre Vontade e Representação, na cosmologia schopenhaeuriana, bem como de atenuar os flertes com o cristianismo, implicados em sua defesa de uma significação moral do mundo. Meu interesse não reside em discutir o como, o porquê, o para que fim, etc, da "relação" entre os estratos epistemológico e metafísico no pensamento de Schopenhauer. Conheço e aceito a posição e o veto do autor àqueles que pretenderam sequer ousar a formulação da questão acerca da relação entre Vontade e Representação. Aqui, ficarei no Epistolário. Numa carta a Adam Ludwig von Doss, de 10 de maio de 1852, ele afirma que, sobre "a história da coisa em si", ele não tem nada a declarar. Ainda a von Doss, em 22 de julho, ao reforçar a impossibilidade de se colocar, seriamente, a pergunta sobre a relação entre Vontade e Representação, pergunta que todo "homem pensante que estudou sua filosofia deve superar", ele afirma: "duvido muito que alguém chegue algum dia mais longe que eu em profundidade: certamente, poder-se-ão corrigir muita coisa no caminho, como argumentos, explicações, demonstrações, ilação de ideias, etc". No entanto, como todos sabemos, lembrados inicialmente pela Prof ${ }^{a}$ M. L. Cacciola, é numa carta a Julius Frauenstädt, de 21 de agosto de 1852, que Schopenhauer nos diz que a Vontade/coisa em si não é: o eterno, o que não tem origem ou o incorruptível ser primogênito. Porém, o mais importante nesta carta é a passagem em que o autor afirma ao pai fundador e apóstolo Frauenstädt que, "o que significa a coisa em si", este deve aprender na Crítica da razão pura; mas o que ela é, deve aprender em sua obra, sobretudo no primeiro tomo dos Parerga; e, sobre qualquer tentativa de interpretar sua filosofia seguindo os rastros dos investigadores do absoluto, dos defensores da prova cosmológica, ele lembra, enfaticamente, como deve ser compreendida sua posição:

Minha filosofia decifra o mundo existente como uma tábua de hieróglifos (cujo código eu achei na Vontade) e mostra sua absoluta coesão. Minha filosofia ensina o que é a coisa em si e suas manifestações. O que é a coisa em si, no entanto, somente se entende em relação com suas manifestações e 
vice-versa. As manifestações, por outro lado, são somente um fenômeno cerebral. Eu nunca falei sobre o que é a coisa em si independentemente dessa relação porque não o sei: nesta relação, em contrapartida, a coisa em si é a vontade de vida (....) O que a coisa em si seja à parte, quer dizer, o que seja independentemente daquilo que conhecemos como vontade de vida, como núcleo da manifestação, quando esta não se manifesta ou quando deixou de ser, é um problema transcendente... É por isso que, embora a coisa em si se nos revelasse como realmente é, nós não entenderíamos nada dela. (SCHOPENHAUER, 2008, p.159. Grifo nosso) ${ }^{3}$.

No tomo dos Parerga acima referido, a saber, no texto intitulado Esboço de uma história da doutrina do ideal e do real, Schopenhauer, após apresentar sua posição em relação às filosofias dos modernos (Descartes, Spinoza, Berkeley, Leibniz, Wolff, etc), concluirá que um dos grandes resultados de seu pensamento é ter concebido e demonstrado que o absolutamente real (das absolut Reale), a coisa em si, não pode nunca ser dado a nós diretamente (geradezu), desde fora (von außen), mas apenas em sua relação com a representação, ou seja, desde o ponto de vista do ideal ${ }^{4}$. Portanto, Vontade somente se diz em sua relação com a Representação ou, melhor dizendo, do ponto de vista da Representação, a partir da Representação; daí a interdição antecipada a toda tentativa (tentação?) de se perguntar pela Vontade, independentemente de sua relatividade (à Representação). Mas a questão permanece: como compreender, então, a Vontade dita em sua relação com a Representação? Falar em essência, interior, núcleo e coisas semelhantes, como faz recorrentemente Schopenhauer, parece-nos antes obscurecer que clarear o problema. Sobretudo por que, desde os trabalhos de R. Haym ${ }^{5}$, já em 1865/66, e G. Riconda ${ }^{6}$, na década de 1980, parece tornar-se patente que, quanto mais levarmos a sério a tese da Vontade/coisa em si como essência, mais nos enrolaremos com o problema da compatibilização entre a teoria do conhecimento e a metafísica schopenhauerianos. Portanto, se por um lado, realmente, devemos respeitar a separação toto genere entre Vontade e Representação, por outro, não podemos nos esquivar das passagens em que o autor afirma que a primeira produz (hervorbringt) para si o segundo, manifesta-se no segundo, etc. Minha posição: a Vontade apresenta-se, no mundo como Representação, enquanto sua significação. A Vontade é a instância de significação dos fenômenos. A filosofia de Schopenhauer seria, finalmente, uma hermenêutica da representação (Daseinshermeneutik) ${ }^{7}$ ou uma hermenêutica da experiência (Herméneutique de l'expérience) ${ }^{8}$.

Como argumentar a favor de tal posição? Quanto ao primeiro ponto, trata-se de compreender que a pergunta pelo ser subjetivo Do meu ponto de vista, a partir de uma 
quádrupla frente: 1) levando a sério a distinção schopenhaueriana entre ser subjetivo e ser objetivo, bem como, no interior deste último, entre consideração subjetiva e objetiva $^{9}$; 2) a partir daquilo que chamei de tese da inteligibilidade inversa ${ }^{10}$; 3) concebendo o processo de objetivação da Vontade nos moldes de uma teoria dos mundos possíveis; 4) compreendendo a matéria (Materie) como noção-limite da filosofia schopenhaueriana e, esta, como uma filosofia do limite. de todas as coisas traduz-se na pergunta pela Vontade, ou pela coisa em si, cuja resposta, na sintonia fina da fala de Schopenhauer, remete-nos, analogicamente, ao território do simbólico, da significação, em uma palavra: à hermenêutica. A segunda ideia aponta para a possível articulação entre o que se pode explicar e o que se trata de compreender: a relação "proporcionalmente" invertida entre a intelecção e a compreensão; a relação possível entre a causalidade como aquilo que explicamos mas não apreendemos o sentido, e o motivo como aquilo que compreendemos o significado mas a nós permanece inexplicável. Uma passagem sugestiva:

\begin{abstract}
Dirigindo inteiramente agora nossa atenção à representação intuitiva, ansiamos (verlangen) conhecer seu conteúdo (Inhalt), suas determinações mais precisas e as figuras que exibem para nós. Será de especial importância obtermos um esclarecimento sobre a significação própria (eigentliche Bedeutung) dessa imagens, para que as mesmas, como teria de ser se sua significação fosse, ao contrário, apenas sentida, não passem diante de nós totalmente estranhas e insignificantes, mas nos falem diretamente, sejam entendidas e adquiram um interesse que absorva todo o nosso ser (SCHOPENHAUER, SW, 2003, p. 151).
\end{abstract}

Esta passagem, no início do segundo livro de $O$ mundo, não obteve, por parte dos intérpretes, a atenção que merece. Ela anuncia aquilo que o referido livro deve explicitar: o que significa o mundo considerado como Representação. Se no primeiro livro o autor discutiu como chegamos a conhecer o mundo e, assim, a saber que nosso mundo liga-se, de modo fundamental, à maneira como nos relacionamos cognitivamente com ele; no segundo livro, a questão é completamente outra; Schopenhauer pergunta: e daí que o mundo é a representação do sujeito! Para que isto aponta? O que isso espelha? O que traduz? Em uma palavra: o que isto significa? É, assim, uma problemática hermenêutica que aqui se inicia e cuja solução passará pela Metafísica da Natureza, a qual, segundo penso, reflete um interesse hermenêutico de fundo. Mas ele prossegue: 
Ao dirigirmos o nosso olhar para a matemática, para a ciência da natureza, para a filosofia, cada uma delas nos deixa esperançosos por obtermos uma parte do desejado esclarecimento (gewünschten Aufsclusses). Entretanto, em primeiro lugar, encontramos a filosofia como um monstro de muitas cabeças, cada qual falando sua própria língua. Certamente nem todas discordam entre si sobre o ponto aqui tratado, o significado (Bedeutung) da representação intuitiva (anschaulichen Vorstellung) (SCHOPENHAUER, SW, 2003, p. 151).

Mais a frente, no parágrafo seguinte, ele procura, positivamente, mesmo que isso se revele futuramente como problemático, dar visibilidade à significação do mundo como Representação. Este exibe, espelha, mostra, manifesta, exterioriza, objetiva.....apresenta algo que não pode ser representado: seu sentido, sua significação. O mundo como Representação, assim, não pode representar aquilo que nele se apresenta; não podemos conhecer, mediante nenhuma classe do princípio de razão suficiente, aquilo que compreendemos. Porém, tudo isso não é assim, ou seja, o fato de não podermos conhecer o mundo como Vontade, não quer dizer que não podemos saber nada acerca dele: nós compreendemos sua significação, ainda que não tenhamos possibilidade de fornecer para isso nenhuma explicação.

\footnotetext{
Mas tudo isso não é assim (apenas representação): a palavra do enigma (Rätsel) é dada ao sujeito do conhecimento que aparece como indivíduo. Esta palavra chama-se Vontade. Esta, e tão somente esta, fornece-lhe a chave (Schlüssel) para o seu próprio fenômeno, revela-lhe (offenbart) a significação (Bedeutung), mostra-lhe (zeigt) a engrenagem interior (innere Getriebe) de seu ser, de seu agir e de seu movimento (SCHOPENHAUER, SW, 2003, p. 156-7).
}

Isto irá implicar a exigência, presente nos Complementos a $O$ mundo e sobretudo nos Parerga, da tese cosmológica da significação moral do mundo.

Porém, justamente aquela idéia, que o mundo tem somente uma significação física e não moral (daß die Welt bloß eine physische, keine moralische Bedeutung habe), constitui o erro mais funesto (der heilloseste Irrtum), nascida da máxima perversidade do espírito (entsprungen aus der größten Perversität des Geistes) (SCHOPENHAUER, SW, 2003, p. 122).

E a consequente distinção de perspectiva ou mesmo de estatuto entre o mundo que podemos conhecer e explicar e o mundo que podemos compreender e interpretar. Isto levará ainda à posição de Schopenhauer acerca da relação entre filosofia e sabedoria, mas isto ultrapassa os limites deste pequeníssimo texto.

...por mais seguro que seja o sentimento de uma significação moral do mundo (Gefühl einer moralischen Bedeutung der Welt) e da vida, resulta tão difícil explicá-la e interpretar a contradição entre ela e o curso do mundo que julgo 
poder reservar-me o direito de expor o verdadeiro fundamento da moralidade - o único autêntico e puro, e por isso eficaz em todo tempo e lugar -, assim como o fim a que conduz; nisso tenho a realidade do processo moral a meu favor para preocupar-me de que esta teoria seja alguma vez substituída e desmentida por outra (SCHOPENHAUER, SW, 2003, p. 238-9).

Distinção que não encontramos apenas nos assim chamados escritos filosóficos menores (Kleine philosophische Schriften), de 1851, os Parerga, mas igualmente no segundo tomo de $O$ mundo. Aqui, vemos que a disjunção entre conhecer e compreender está intimamente vinculada à distinção entre ser subjetivo e ser objetivo; separação que não deve, de maneira nenhuma, ser pensada como equivalente àquela existente entre consideração ou ponto de vista subjetivo e objetivo.

...todo conhecer (Erkennen) é essencialmente um representar (Vorstellen): mas meu representar, exatamente porque é meu, nunca pode ser idêntico ao ser em si (Wesen an sich) da coisa (Dinges) exterior a mim. O ser em si e por si (An-und-Für-sich-sein) de todas as coisas deve necessariamente ser subjetivo (subjektives): na representação de um outro, em contrapartida, apresenta-se (steht...da) com igual necessidade como objetivo (objektives); uma distinção que jamais pode ser totalmente compensada (SCHOPENHAUER, SW, 2003, p. 250-1, grifo nosso).

Ou um pouco mais a frente:

Se, indo mais fundo na investigação, intuo corpos inertes (leblose) de magnitude facilmente apreciável e de forma regular, e logo intento conceber sua existência espacial em suas três dimensões como o ser em si (Sein an sich), consequentemente, como a existência subjetiva das coisas (Dingen subjektive Dasein), ser-me-á imediatamente evidente a impossibilidade de uma tal tentativa; porque assim já não posso pensar aquelas formas objetivas (objektiven Formen) como o ser subjetivo das coisas (Dingen subjektive Sein), senão que sou imediatamente convencido de que o que eu assim me represento é uma imagem (Bild) produzida em meu cérebro, que somente existe para mim enquanto sujeito cognoscente e que não pode constituir o ser em si e por si último e subjetivo (SCHOPENHAUER, SW, 2003, p. 251, grifo nosso).

Distinção que, claro, será reafirmada no texto de 1851:

A diferença entre coisa em si e fenômeno pode ser expressa também como a diferença entre o ser subjetivo e objetivo de uma coisa (subjektiven und objektiven Wesen eines Dinges). Seu ser puramente subjetivo é, justamente, a coisa em si (sein rein subjektiven Wesen ist eben das Ding an sich): mas esta não é nenhum objeto (Gegenstand) de conhecimento. Pois para um objeto é essencial existir sempre em uma consciência cognoscente (erkennenden Bewußtsein) como sua representação: e o que aí se apresenta é justamente o ser objetivo da coisa (das objektive Wesen des Dinges). Este é, por conseguinte, objeto do conhecimento; mas, enquanto tal, é tão somente uma representação (SCHOPENHAUER, SW, 2003, p. 112-113. 
Uma terceira frente em que podemos nos colocar para atenuar os compromissos com a tese da significação moral do mundo é, como afirmei acima, interpretar a objetivação da Vontade como uma modalidade da teoria dos mundos possíveis afinal, Schopenhauer não afirma, nem pode afirmar, que a Vontade, livre, seria determinada, necessariamente, a se objetivar de uma única e invariável maneira, na multiplicidade de seus fenômenos. O que ele diz, insistentemente, é que se trata de uma única e mesma Vontade, que se manifesta, reflete-se, exterioriza-se em uma miríade de espécies e indivíduos, o que implica, pensamos, que o mundo, qualquer que seja ele, conforme Schopenhauer, tem sempre uma significação, mas não que em todos eles (os mundos) ela seja moral, ou mesmo que, quando moral, ela valha para a totalidade do mundo, pois pensamos que, neste caso, as noções de conflito e impulso cego são mais fundamentais que as de negação e de superação/supressão. Mais ainda, em um mesmo mundo, o nosso, por exemplo, poder-se-ia pensar uma mesma e única Vontade se objetivando, simultaneamente, de infinitas formas, o que, no limite, abriria a possibilidade de uma significação afirmativa, não moral, do mundo. Claro, tudo isso, como já se disse, pode ser apenas o sonho de um visionário, o delírio de um louco ou os passos cambaleantes de um sonâmbulo.

Uma quarta perspectiva, atenuante para o idealismo schopenhaueriano, reside em uma certa compreensão da significação de sua noção de matéria ${ }^{11}$. A noção de matéria recebe um significativo aprofundamento no segundo volume de $O$ mundo. $\mathrm{O}$ mais emblemático, na complexificação do referido conceito, podemos verificar na tábua dos Praedicabilia a priori, apresentada ao término do capítulo 4, sobre o conhecimento a priori. Ali, ficamos sabendo que matéria é tanto a Materie quanto o Stoff. Na diferenciação entre os significados de ambos, Schopenhauer fazia amplo uso de termos aristotélico-escolásticos, porém em um sentido que, dificilmente, poderia ser considerado coincidente com aqueles empreendidos pela tradição realista que os fez nascer e os desenvolveu. Além disso, somos informados que os verdadeiros polos da representação são, não o sujeito e objeto, forma geral de toda representação, conforme o Livro I de $O$ mundo, mas sujeito puro (reinen Subjekt) e matéria (Materie). Por sua vez, no capítulo 24, intitulado: Da matéria (Von der Materie), descobrimos o papel, absolutamente fundamental, que semelhante conceito representa na teoria da objetivação da Vontade e, através disso, no cerne do procedimento analógico. 
O que está em jogo aqui parece ser o fato de Schopenhauer ter-se deparado com a verdadeira intenção da arquitetônica kantiana e, claro, não ter conseguido sentir nenhuma atração por ela: em Kant, o problema do limite do conhecimento tende a ser resolvido ou atenuado por uma filosofia da esperança, a ordem prática (Praktische) operando como fio condutor (Leitfaden) para a solução (Beantwortung) das questões teóricas (theoretischen) e, acima destas, das especulativas (spekulativen) (A806;B834): ou Kant fazia isso ou a primeira crítica terminaria totalmente negativa e des-esperada. Ora, Schopenhauer aceita o des-espero oriundo da Crítica da razão pura, mas tenta superá-lo sem o apelo a uma filosofia da esperança. No entanto, para a solução do problema, não pode retornar ao antigo dogmatismo, à con-fusão entre fenômenos e coisa em si. O que ele faz: concebe o corpo como espelho e manifestação do sentido do mundo; como manancial hermenêutico em que se pode des-cobrir e des-velar a significação profunda do Real.

Como de um significado não se deve exigir a mesma coisa que de uma explicação, então, esperar da filosofia schopenhaueriana que ela não oscile e não seja permeável a certas ambigüidades seria privilegiar aquilo que para ela é o mais fundamental, e não o mais importante, isto é, a tentativa de encontrar uma significação moral para o mundo, sem que com isso tenha-se que se ajoelhar ou esperar por uma vida bem aventurada após a morte - no caso de termos feito aquilo que devíamos e conhecido aquilo que podíamos.

A matéria será, entretanto, aquilo que de mais profundo podemos postular como condição de todo conhecimento, já que ela não é objeto, mas condição da objetividade do nosso conhecimento de objetos; enquanto a Vontade, eternamente incognoscível, é o que de mais íntimo podemos compreender. Do sujeito e objeto, ambos pertencentes ao ser objetivo das coisas, apenas considerado, este último, ora subjetivamente, ora objetivamente, como forma geral da Representação, passaremos à matéria (ser objetivo) e à Vontade (ser subjetivo), não como forma geral da Representação, mas como condição primeiro-última de toda intelecção (matéria), e como condição ineliminável de toda compreensão (Vontade).

Portanto, sem que a matéria pudesse ser pensada como limite de todo ser objetivo e de todo ponto de vista objetivo acerca do mundo, o salto na direção do ser subjetivo seria muito mais longo, senão impossível. Claro que isso não elimina o problema do grande pressuposto apontado por Schopenhauer, no momento mesmo em 
que este se lança no mar de significação aberto pela concepção da Vontade como coisa em si e ser subjetivo de todas as coisas: trata-se da afirmação de que aquilo que vale (gilt) para a Vontade em si vale, igualmente, para as suas objetivações, isto é, para aquilo que podemos experimentar. Ele chega a dizer que os fenômenos da Vontade reproduzem mesmo todas as relações (Beziehungen) e propriedades (Eigenschaften) desta, conforme dissemos acima. Ora, isso parece transgredir em muito a interdição que sua própria filosofia havia posto desde o início.

Em todo caso, sem isso, sem pressupor tal espelhamento, é impossível tomar a matéria (Materie) como ponto de contato (Band) entre o ser objetivo e o ser subjetivo e, assim, afirmar, como ele, que o que subjetivamente é Vontade, objetivamente é matéria. Esta somente pode ser a condição objetiva de todo o processo de objetivação da Vontade e, assim, condição primeiro-última de possibilidade de todo conhecimento objetivo, se a Vontade, enquanto ser subjetivo de todas as coisas, for a condição de significação de todos os seus fenômenos, de todas as suas objetivações.

Aqui, evidentemente, apenas formulo minha hipótese de leitura do estatuto da concepção schopenhaueriana da Vontade e aponto para aquilo que pode ser utilizado como horizonte teórico para a tentativa de verificação da viabilidade da minha posição ${ }^{12}$. Entretanto, se articularmos as três perspectivas acima sugeridas, penso que a tese acerca da significação moral do mundo será, no mínimo, bastante atenuada e, consequentemente, o próprio estatuto da filosofia schopenhaueriana terá que ser revisado.

\section{Da idiotia: o caso cético}

Será ainda numa carta a Frauenstädt, desta vez a de 30 de outubro de 1851, que podemos encontrar o diagnóstico antecipado que Schopenhauer teria dado à minha patologia: idiotia. Na referida carta, Schopenhauer afirma, acerca de um tal Sr. Voigtländer que, se este é um apóstolo, então deve ser Judas, já que duvidava da idealidade do espaço e do tempo: "uma verdade que somente um idiota pode negar"13. $\mathrm{Na}$ verdade, desde as primeiras interpretações da Crítica kantiana, o problema da idealidade das intuições puras vem sendo discutido. Maimon, Lange, Überweg, Vaihinger e, no Brasil, Bonaccini, são alguns dos que, por diferentes caminhos, problematizaram a legitimidade da posição adotada por Kant: a passagem da tese da 
aprioridade do espaço e do tempo para a da idealidade dos mesmos. Poder-se-ia, no limite, aceitar o caráter apriorístico de ambos sem, com isso, comprometermo-nos com a dimensão subjetiva destes. Aqui, discutirei apenas algumas implicações da hipótese de que, talvez, a suspensão de juízo (epokhé) pirrônica não seja incompatível com uma certa interpretação da filosofia de Schopenhauer. Claro que, com isso, além de idiota, corro o risco de ser acusado de malandragem, ou de simples esperteza, pois, como sabemos pelo $§ 11$, do cap.1, do primeiro tomo dos Parerga, Sobre a filosofia e seu método: "A mera esperteza (bloße Schlauheit) basta para fazer um cético, mas não um filósofo"; pois o ceticismo estaria para a filosofia como a oposição para o governo: seria "tão benéfico (wohltätig) quanto necessário (notwendig)"14.

Seja como for, parece que, também aqui, não sou o primeiro a desconfiar da possibilidade de se fazer dialogar a filosofia de Schopenhauer com uma certa tradição do ceticismo antigo, em especial, o de rosto pirrônico ${ }^{15}$. Dieter Birnbacher ${ }^{16}$, seguindo as pegadas de Martin Morgenstern ${ }^{17}$, fala daquilo que, numa tradução um tanto livre, seria uma potência suspensiva (epochemachende Leistung), para diferenciar as significações das noções de metafísica em Kant e Schopenhauer. Realmente, segundo Birnbacher, a metafísica schopenhaueriana da suposição (Vermutungsmetaphysik), metafísica indutiva (induktive Metaphysik), segundo Oswald Külpe, parece ter como alvo mais a profundidade que a universalidade, ter mais compromisso real com a experiência do que as suas adversárias de ascendência kantiana. O próprio Nietzsche, ao tentar atenuar as críticas de Haym à filosofia de seu educador, distingue, conforme as motivações do ceticismo antigo, a perspectiva metódica, problemática em Schopenhauer, da motivação ética, ancorada no imperativo de honestidade intelectual e na concepção de metafísica enquanto ficção conceitual para fins edificantes ${ }^{18}$. O que farei aqui é tentar projetar uma porta de entrada/saída cética para a cosmologia do autor de $O$ mundo.

A cosmologia de Schopenhauer já se anuncia no título e no sumário de sua obra magna: $O$ mundo como vontade e como representação ${ }^{19}$. Eles nos apontam a tarefa e a estratégia fundamentais que o autor pôs para a sua filosofia. A tarefa: construir uma teoria do mundo: 1) por um lado, descrever a maneira como nos relacionamos com este, como o mesmo se nos apresenta, ou melhor, como nós o representamos; 2) uma vez que não podemos jamais representar aquilo que nele se apresenta, então resta-nos decifrar sua significação profunda, seu segredo insondável (unergründlisches 
Geheimnis), ou seja, construir uma via subterrânea (unterirdischer Gang) na qual se possa, por meio de uma certa traição (Verrat), tentar, ainda que desesperadamente, uma conexão secreta (geheime Verbindung) com a significação moral do mundo. A estratégia: articular dois pontos de vista (Gesichtspunkt) e duas considerações (Betrachtungen). Os dois pontos de vista: Vontade e Representação; as duas considerações operando dentro dos pontos de vista de maneira distinta. A possibilidade do ceticismo aparece, na teoria, quando o problema cosmológico exige que nos coloquemos no entrecruzamento dos pontos de vista. O ceticismo torna-se uma possibilidade quando comparamos, por exemplo, o Livro I do primeiro tomo de $O$ mundo, com o $\$ 85$, do cap.6, do segundo tomo dos Parerga, intitulado: Sobre a filosofia e a ciência da natureza, .

Trata-se da objetividade de nosso conhecimento. Para Schopenhauer, o ser objetivo (dos objetos), para ser conhecido, depende da oscilação de uma dupla perspectiva: uma formal-subjetiva e outra material-objetiva. Isto implica que a objetividade de nosso saber depende, formal e constitutivamente, do sujeito cognoscente; "conteudalmente", da matéria "do" objeto. Daí, para Schopenhauer, "antes" do primeiro ser cognoscente (sujeito) abrir o olho, nada de objetivo poder-se-ia dizer/conhecer do mundo. O problema: como conciliar esta posição com a aceitação schopenhaueriana da tese cosmológica (kosmogonich) da nebulosa de Kant-Laplace? Poder-se-ia afirmar algo sobre o mundo "antes" da abertura do primeiro olho? Sim, algo acerca do ser subjetivo do mundo. Poderíamos dizer: que o mundo seria seu ser subjetivo, seria Vontade; mas para isto seria preciso uma, por assim dizer, cláusula de tolerância. A cláusula teria que existir porque, como a Vontade somente se diz em relação à Representação, então, a rigor, na ausência desta última, "antes" da abertura do primeiro olho, rigorosamente nada poder-se-ia dizer ${ }^{20}$. Acontece que, aqui, o senso comum não apenas exige seus direitos como o filósofo não deveria fugir de seu dever de justificar sua posição, tornando-se, caso contrário, o silêncio um sintoma. A tese da idealidade do tempo impede qualquer tentativa de aproximação da questão, daí a oscilação de Schopenhauer, que ora pretende falar hipoteticamente, ora se proíbe até mesmo isso. Ele sabe que se pode apontar uma existência anterior ao sujeito, mas negase a falar sobre ela.

O mundo anterior ao sujeito cognoscente não é uma hipótese: 
...o mundo objetivo (objektive Welt) existe somente (nur) como representação (als Vorstellung), não é uma hipótese (ist keine Hypothese), e ainda menos uma decisão autoritária (Machtspruch) ou um paradoxo (Paradoxon) levantado por razões de disputa (disputierenshalber); pelo contário, é a verdade mais certa e simples (gewisseste und einfachste Wahrheit), cujo conhecimento somente é dificultado pelo fato de que é demasiado fácil e nem todos têm capacidade suficiente de reflexão para retroceder até os primeiros elementos de sua consciência das coisas. De modo algum (nimmermehr) pode existir uma existência absoluta e objetiva em si mesma (ein absolut und an sich selbst objektives Dasein); semelhante coisa é, inclusive, impensável (undenkbar): pois o objetivo, enquanto tal (Objektive als solches), tem sempre e essencialmente sua existência na consciência de um sujeito (seine Existenz im Bewußtsein eines Subjekts), portanto é sua representação e, por conseguinte, está condicionada (bedingt) por ele e por suas formas da representação, as quais dependem do sujeito e não do objeto (SCHOPENHAUER, SW, 2003, p. 13-14, grifo nosso).

O mundo anterior ao sujeito é em parte uma hipótese:

Admito que tudo o que disse aqui deve ser considerado, na realidade (eigentlich), como meras imagens (nur Bild) e comparações (Gleichnis), também em parte hipóteses (zum Teil hypothetisch). Porém, nos encontramos em um ponto ao qual apenas alcançam os pensamentos... (SCHOPENHAUER, SW, 2003, p. 360, grifo nosso).

Daí a conclusão, para mim, difícil de aceitar:

\begin{abstract}
Se tivermos de admitir, por um lado, há que convir que todos aqueles processos físicos, cosmogônicos, químicos e geológicos, dado que tiveram que preceder, necessariamente, à irrupção de uma consciência enquanto condições suas, existiram também antes desta irrupção, quer dizer, fora de uma consciência; porém, por outro lado, não se pode negar que justamente os mencionados processos, posto que não podem apresentar-se mais que nestas formas e através delas, fora de uma consciência não são absolutamente nada, não se podem nem sequer pensar. Em resumo, poder-se-ia dizer: a consciência condiciona os processos físicos em questão segundo suas formas; porém, por sua vez, está condicionada por eles segundo sua matéria (Materie). No fundo, porém, todos aqueles processos que a cosmogonia e geologia nos obrigam a pressupor como tendo ocorrido bem antes da existência de um ser cognoscente são apenas a tradução para a linguagem de nosso intelecto intuitivo daquela essência em si das coisas que ele não pode compreender. Pois esses processos jamais tiveram uma existência em si mesma, não mais que os fatos atuais (SCHOPENHAUER, SW, 2003, p. 167, grifo nosso).
\end{abstract}

Ora, o que realmente aconteceria se jogássemos fora a tese da idealidade e tornássemo-nos conscientemente idiotas? Se mantivéssemos a tese da aprioridade, e nada impediria que a conservássemos, então, penso, teríamos uma destas alternativas: 1) a necessidade de reconstruir a teoria da representação intuitiva em outros marcos, pois o tempo (também o espaço), agora não ideal, exigiria uma nova concepção da matéria e, assim, talvez a ameaça do materialismo ressurgisse mais fortemente; 2) a opção de 
suspendermos o juízo. Gostaria de avançar um pouquinho neste último possível programa.

A epokhé da tese da idealidade não implica nem a tese da não-idealidade nem a da afirmação da realidade do tempo. Ela exige que se afirme a ignorância acerca da suposta idealidade e que se considere, consequentemente, tudo aquilo que sobre ela se construir, como hipotética, ou seja, como uma ficção, para falar com Haym e Lange, ou uma fantasia, para ficarmos com Paul Rée. Ficção ou fantasia que, em última instância, acabam por desempenhar quase o mesmo papel que aquele desempenhado pela posição schopenhaueriana ortodoxa, qual seja: servir de plataforma de lançamento para uma defesa da significação moral do mundo. Trata-se de saber, no final do dia, o que seria o fundamental para Schopenhauer. Fico com ele, embora talvez contra ele mesmo, quando nos diz, no segundo tomo de $O$ mundo, cap.23, Sobre a objetivação da Vontade na natureza carente de conhecimento, que os dois primeiros e fundamentais passos (Schritt) para se compreender a sua filosofia são: o primeiro, a separação toto genere entre Representação e Vontade, sendo aquela secundária em relação a esta; o segundo, a compreensão de que uma mesma e una Vontade objetiva-se na natureza através de forças naturais (SCHOPENHAUER, SW, 2003, p. 378). Acredito que, para todo aquele que pretende movimentar-se, de alguma forma, no território desbravado por Schopenhauer, serem esses passos "o inegociável", "o fundo do poço". Bem, nenhum deles impede a suspensão do juízo acerca da idealidade do tempo e, por outro lado, o que se ganharia com esta suspensão, se a acoplamos a uma leitura hermenêutica da Vontade, compreendida como instância de significação da existência, é nada mais nada menos que a possibilidade de superação do debate em torno do conflito entre a teoria do conhecimento e a metafísica schopenhauerianos; conflito este que se arrasta, no mínimo, desde a década de 60 do século XIX, a partir dos trabalhos de Rudolf Haym.

Por fim, lembro que aqui apenas apontei e acenei para um possível diálogo entre a posição de Schopenhauer e aquela aberta por Pirro de Élida (século III a.c.). Gostaria de evitar duas interpretações: 1) que se pense que afirmo a existência de um Schopenhauer cético: isso não é o caso; motivo pelo qual antecipei um seu possível diagnóstico em relação à minha posição: herético e idiota; 2) que se pense que a única porta para a interlocução seja via cosmologia; afinal, quando Sexto Empírico, em suas Hipotiposis pirrônicas, no cap. XII, Do fim do ceticismo, afirma que a finalidade do ceticismo, em relação àquilo que é necessário, é a moderação (metriopátheia), 
pensamos que ele não está muito longe daquilo que Nietzsche, seguindo seu educador, enaltecia como modo de ser do filósofo, a saber, a serenidade (Heiterkeit), jovialidade (Jair Barboza) ou serenojovialidade (Paulo Cesar Souza). Mas isso, claro, é uma outra conversa. 


\section{Notas:}

${ }^{1}$ Professor Adjunto da Universidade Estadual do Ceará (UECE), Brasil. e-mail: ruydec@outlook.com

${ }^{2}$ Cf., Fichte, Comunicado claro como o Sol ao grande público, onde se mostra em que consiste propriamente a Novissima Filosofia. In: FICHTE, Johann Gottlieb; SCHELLING, Friedrich Von. Escritos filosóficos. Trad. Rubens Rodrigues Torres Filho. São Paulo: Abril Cultural, 1973. (Col. "Os Pensadores").

${ }^{3}$ A Prof ${ }^{a}$ Maria Lúcia Cacciola, ao interpretar esta passagem da carta citada, afirma que aqui estaria a advertência schopenhaueriana na compreensão da Vontade como coisa em si. A Vontade como coisa em si somente pode ser compreendida na relação com a representação, nunca absoluta e independentemente desta. Claro, procurar compreender a Vontade, absolutamente, tornaria a filosofia de Schopenhauer vulnerável às acusações de dogmatismo e de retorno a um horizonte pré-crítico. (CACCIOLA, 1994, p.115).

${ }^{4}$ Cf., Schopenhauer, Parerga, I, Skisse einer Geschichte der Lehre vom Idealen und Realen, p.31. In.: SCHOPENHAUER, Arthur. Sämtliche Werke $(S W)$. Editadas e comentadas por Wolfang Frhr. von Lohneysen. Suhrkamp taschenbuch wissenschaft, 2003. 5 vols, vol.4. Neste artigo utilizamos, para $O$ mundo como vontade e como representação, o original em alemão e a tradução brasileira do Prof. Jair Barboza.

${ }^{5}$ Cf., HAYM, R. Arthur Schopenhauer. In.: Gesammelte Aufsätze. Berlin, Weidmann, 1903, pp.239-355.

${ }^{6}$ Cf., RICONDA, G. Schopenhauer interprete dell'occidente, Milão, Mursia (Gruppo Editoriale), 1986.

${ }^{7}$ Cf. SAFRANSKI, R., Schopenhauer und Die wilden Jahre der Philosophie. Eine Biographie, Frankfurt am Maim, Fischer Taschenbuch Verlag, 2008, Cap. 15, p.320. Cf. tb. Cap.14, pp.305-306, onde Safranski interpreta a metafísica da Vontade schopenhaueriana como uma hermenêutica da existência (Hermeneutik des Daseins); uma metafísica mais interessada em compreender (Verstehen) o significado (Bedeutung) da totalidade do mundo do que em explicar (Erklären) as relações causais; em elucidar "o que" (was) é o mundo em sua significação profunda do que em interrogar o "por que" (Warum) das ocorrências fenomênicas.

${ }^{8}$ Cf. BARBERA, Sandro., Une philosophie du conflit. Études sur Schopenhauer, Paris, Presses Universitaires de France (PUF), 2004, p.73-76.

${ }^{9}$ Sobre isso, cf., Schopenhauer, SW, I, §§17-23; Anhang, p.578; SW, II, cap.1, Sobre o ponto de vista fundamental idealista, p. 25; cap. 7, Da relação do conhecimento intuitivo com o abstrato, p. 114; cap.17, Sobre a necessidade metafísica dos homens; cap.18, Da cognoscibilidade da coisa em si, pp.250-3; SW, III, A vontade diante da consciência das outras coisas, p.566; Parerga, II, SW, V, cap.1, A filosofia e seu método, §1, p. 9; cap.4, Algumas considerações sobre a oposição entre a coisa em si e o fenômeno, §64, p.112-113.

${ }^{10}$ Cf., CARVALHO, Ruy de. Schopenhauer: uma filosofia do limite. Tese de Doutorado defendida na Pontifícia Universidade Católica de São Paulo, Departamento de Filosofia, sob a orientação do Prof. Dr. Ivo Assad Ibri, 2011; SW, III, Da quádrupla raiz, cap.7, Sobre a quarta classe de objetos para o sujeito, $\S 41$, p.168; SW, III, Sobre a Vontade na natureza, cap., Astronomia fisica, p. 409-15; SW, V, cap.4, Algumas considerações sobre a oposição entre a coisa em si e o fenômeno, §64, p. 113;

${ }^{11}$ Sobre a significação e o papel da noção de matéria na obra de Schopenhauer temos, no Brasil, o importante trabalho de Eduardo Brandão. Cf. E. Brandão, A concepção de matéria na obra de Schopenhauer. São Paulo: Humanitas, 2009.

${ }^{12}$ Sobre a minha posição a respeito do tema, cf. CARVALHO, R.. Schopenhauer: uma filosofia do limite. Tese cit. 
${ }^{13}$ Cf., Cartas desde la obstinación, p.152. Trad. Eduardo Charpenel Elorduy. México: Los Libros de Homero, 2008.

${ }^{14}$ Cf. Parerga, II, SW, V, cap.1, §1, Sobre a filosofia e seu método, p.9. Seguimos aqui a tradução de Flamarion C. Ramos, in.: Schopenhauer, A filosofia e seu método, São Paulo, Hedra, 2010, p.39.

${ }^{15}$ Sobre as dificuldades e tarefas a serem resolvidas na tentativa de se conceber o estatuto, a significação e os limites do ceticismo de Pirro, bem como da recepção e construção deste ceticismo por Enesidemo, Agripa e Sexto, cf., além do clássico Os céticos gregos, de Victor Brochard, o excelente trabalho de Gabriela Gazzinelli, A vida cética de Pirro, São Paulo, Loyola, 2009.

${ }^{16}$ Cf., D. Birnbacher, Schopenhauer, Stuttgart, Reclam, 2009.

${ }^{17}$ Cf., M. Morgenstern, Schopenhauers Begriff der Metaphysik und seine Bedeutung für die Philosophie des 19.Jahrhunderts. Zeitschrift für philosophiche Forschung 41, 1987, p.592-612.

${ }^{18}$ Sobre as motivações do ceticismo antigo, bem como sobre a metafísica enquanto "ficção conceitual para fins edificantes", cf., R. Lopes, Ceticismo e vida contemplativa em Nietzsche, Tese de Doutorado defendida na Universidade Federal de Minas Gerais, Faculdade de Filosofia e Ciências Humanas, Departamento de Filosofia, sob a orientação do Prof. Dr. José Raimundo Maia Neto, 2008. Sobre a posição de Nietzsche, cf., a carta a Von Gersdorff, final de agosto de 1866.

${ }^{19}$ Sobre o estatuto cosmológico da filosofia do autor de $O$ mundo, cf., Cf. Schopenhauer, $O$ mundo como vontade e como representação, II, in: SW, II, Cap. 48, Para a doutrina da negação da vontade de vida, p.783.

${ }^{20}$ Algo parecido acontece com a divisão da filosofia oferecida por Schopenhauer no $\$ 10$, do cap.1, do tomo II dos Parerga, em que o autor, após dividir as teorias filosóficas em racionalismo e iluminismo, afirma que, ao final de sua filosofia, fim do $\$ 71$ de $O$ mundo, apenas indicou "o âmbito do iluminismo/misticismo como algo existente", mas que teria se resguardado "de dar um único passo sequer em seu terreno". Cf., Schopenhauer, $S W$, V, cap.1, Sobre a filosofia e seu método, §10, p.38. 


\section{Referências}

BARBERA, S. Une philosophie du conflit. Études sur Schopenhauer. Paris: PUF, 2004.

BIRNBACHER, D. Schopenhauer. Stuttgart: Reclam, 2009.

BRANDÃO, E. A concepção de matéria na obra de Schopenhauer. São Paulo: Humanitas, 2009.

CACCIOLA, M. L. M. O. Schopenhauer e a questão do dogmatismo. São Paulo: Edusp, 1994.

FAZIO, D. A escola de Schopenhauer. In.: Nietzsche-Schopenhauer. Metafisica e significação moral do mundo. Tomo 2. Desdobramentos. Organizadores: Ruy de Carvalho, Gustavo Costa e Thiago Mota. Fortaleza: EdUECE, 2014.

FICHTE, G. Comunicado claro como o Sol ao grande público, onde se mostra em que consiste propriamente a Novíssima Filosofia. In: FICHTE, Johann Gottlieb; SCHELLING, Friedrich Von. Escritos filosóficos. Trad. Rubens Rodrigues Torres Filho. São Paulo: Abril Cultural, 1973. (Col. "Os Pensadores").

GAZZINLLI, G. A vida cética de Pirro. São Paulo: Loyola, 2009.

HAYM, R. Arthur Schopenhauer. In.: Gesammelte Aufsätze. Berlin: Weidmann, 1903, p.239-355.

LOPES, R. Ceticismo e vida contemplativa em Nietzsche, Tese de Doutorado defendida na Universidade Federal de Minas Gerais, Faculdade de Filosofia e Ciências Humanas, Departamento de Filosofia, sob a orientação do Prof. Dr. José Raimundo Maia Neto, 2008.

MORGENSTERN, M. Schopenhauers Begriff der Metaphysik und seine Bedeutung für die Philosophie des 19.Jahrhunderts. Zeitschrift für philosophiche Forschung n.41, 1987.

RICONDA, G. Schopenhauer interprete dell'occidente. Milão: Mursia (Gruppo Editoriale), 1986.

RODRIGUES, R. C. Schopenhauer: uma filosofia do limite. Tese de Doutorado defendida na Pontifícia Universidade Católica de São Paulo, Departamento de Filosofia, sob a orientação do Prof. Dr. Ivo Assad Ibri, 2011.

SAFRANSKI, R. Schopenhauer und Die wilden Jahre der Philosophie. Eine Biographie. Frankfurt am Main: Fischer Taschenbuch Verlag, 2001.

SCHOPENHAUER, Arthur. Sämtliche Werke. Editadas e comentadas por Wolfang Frhr. von Lohneysen. Suhrkamp taschenbuch wissenschaft, 2003. 5 vols. 
O mundo como vontade e como representação. Tomo 1.Trad. Jair Barboza. São Paulo: Unesp, 2005.

Cartas desde la obstinación. Trad. Eduardo Charpenel Elorduy. México: Los

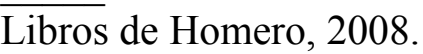

